\title{
Laryngofissure Cordectomy-Evaluations of Positive Margins and Survival Rates
}

Bayram VEYSELLER', Nermin BAŞERER²

'Department of Otorhinolaryngology, Bezmialem Vakıf University School of Medicine, İstanbul, Turkey

${ }^{2}$ Department of Otorhinolaryngology, İstanbul University İstanbul School of Medicine, İstanbul, Turkey

\section{ABSTRACT}

Objective: The primary aim of this study was to evaluate the results of early-stage glottic laryngeal cancer patients who underwent laryngofissure cordectomy. Results were analyzed in terms of positive margins and survival rates.

Methods: This prospective study was conducted on 232 patients (mean age, 55.2 years; range, 34- 76 years) who underwent laryngofissure cordectomy (without tracheotomy) between 1977 and 1996 for T1 glottic carcinoma.

Results: The results of the 167 patients with adequate follow-up were evaluated. Sixteen patients (6.8\%) were detected with one or two positive margins. One patient with three positive margins was reoperated with near total laryngectomy. The remaining 15 patients were closely followed up. Fourteen of the 167 patients (8.3\%) had local recurrence, and $50 \%$ of patients with local recurrence $(\mathrm{n}=7)$ underwent additional partial laryngectomy. In our series, the five-year survival rate was $91.6 \%$ without recurrence and $95.8 \%$ with salvage surgery.

Conclusion: Laryngofissure cordectomy is suitable for the treatment of early-stage tumors because it does not require tracheotomy, has a low cost, and has low complications rates.

Keywords: Laryngeal cancer, early stage, laryngofissure, cordectomy

\section{Introduction}

The most common type of head and neck cancer is laryngeal cancer. It constitutes $1 \%$ of all cancer types (1). Hoarseness, which is the main symptom in laryngeal cancer, helps diagnose the disease in early stages.

The first surgeries performed in the treatment of laryngeal tumor are laryngofissure or thyrotomy. The first cordectomy for laryngeal cancer was performed by Brauers in 1834 (2).

Presently, treatment methods in early-stage glottic laryngeal cancers include radiotherapy, endoscopic surgeries (with or without laser), and laryngofissure cordectomy. Successful results have been reported at rates of over $90 \%$ for all three treatment methods; thus, there is confusion confusion in the choice of treatment (3-9). Early-stage glottic tumors do not decrease vocal cord movement and do not involve the anterior commissure.

\section{Methods}

The files of 232 patients who underwent laryngofissure cordectomy due to a diagnosis of $\mathrm{T} 1$ glottic laryngeal cancer in the Clinic of Otorhinolaryngology Head and Neck Surgery at a tertiary care university hospital between 1977 and 1996 were retrospectively evaluated.

The ages of the patients ranged from 34 years to 76 years (mean: 55.2 years). The age range distribution of the patients according to the decade is presented in Table 1. 
Among the patients, 227 (98.8\%) were males and 5 (2.2\%) were females. The male/female ratio was $45 / 1$. Surgery was performed in 1941 patients diagnosed with laryngeal cancer in our clinic during the same period, and $11.95 \%$ of these patients underwent laryngofissure cordectomy.

Tumors were located on the right side in 134 patients, on the left side in 92, and bilaterally in 6 . Double cordectomy was performed for 6 patients, and unilateral cordectomy was performed for 226. For 9 patients, extended cordectomy was performed including the anterior commissure because the tumor expanded up to the anterior commissure. In 16 patients $(6.8 \%)$, positivity was found in one or two margins. One patient had three positive margins, and this patient underwent near-total laryngectomy. Another 15 patients were closely followed up.

\section{Statistical analysis}

Data were analyzed using SPSS for Windows 10.0. The Wilcoxon rank, paired t-test, and Mann-Whitney $U$ test were used for comparisons, and $\mathrm{p}<0.05$ was considered to be significant.

\section{Results}

Histopathological pre-operative diagnosis was squamous cell carcinoma in all patients. The examination of pathological pieces after cordectomy revealed invasive squamous cell carcinoma in 152 patients, microinvasive cancer in 40 patients, and pathologies ranging from chronic inflammation to severe dysplasia in 40 patients. The distribution and percentages of histopathological diagnoses can be seen in Table 2 .

Of the patients, 179 completed a 5-year follow-up. As they had been followed up adequately, 167 patients were evaluated. Local recurrence was detected in $14(8.3 \%)$ of 167 patients. Phonation was protected by using partial laryngectomy techniques such as near-total laryngectomy in 3 patients, frontal anterior laryngectomy in 3 patients, and horizontovertical laryngectomy in 1 patient. Total laryngectomy was applied in other 6 patients. In $50 \%$ of the patients with local recurrence, the chance of partial laryngectomy was obtained again. On the other hand, one patient who developed a local recurrence accepted salvage surgery, but did not visit for control examinations. It was determined that 10 of 14 patients developing local recurrence continued to smoke. All patients with local recurrence were observed to develop within the first 2 years. The neck dissection was performed unilaterally in 10 of 13 patients developing local recurrence and undergoing salvage surgery. Five patients who underwent total laryngectomy and 1 patient who underwent near-total laryngectomy died due to locoregional recurrences. The remaining 7 patients completed their 5-year survival follow-up without disease after salvage surgery $(53.8 \%)$.

Of the 179 patients, 167 were followed up regularly within the 5-year period $(91.6 \%)$. A 5-year survival was obtained in 161 patients, including the ones saved through salvage surgery $(95.8 \%)$.
Table 1. Age range distribution of patients according to the decade

\begin{tabular}{|l|c|c|}
\hline Age range & Number of patients & $\%$ \\
\hline $31-40$ & 18 & 7.7 \\
$41-50$ & 54 & 23.2 \\
$51-60$ & 99 & 42.6 \\
$61-70$ & 57 & 24.5 \\
$71-80$ & 4 & 2 \\
\hline
\end{tabular}

Table 2. Distribution and percentages of patients' histopathological diagnoses

\begin{tabular}{|l|c|c|}
\hline Histopathology & Number of patients & $\%$ \\
\hline \begin{tabular}{l|l|} 
Invasive squamous \\
cell carcinoma
\end{tabular} & 152 & 65.5 \\
Microinvasive cancer & 40 & 17.2 \\
\hline Severe dysplasia & 18 & 7.7 \\
Chronic inflammation & 22 & 9.4 \\
\hline Total & 232 & 100 \\
\hline
\end{tabular}

Post-operative pathological examination revealed squamous cell carcinoma in $13(92.8 \%)$ of 14 patients developing local recurrence. One patient was evaluated to have carcinoma in situ as a result of examination with double cordectomy. Of 33 patients that were diagnosed with postoperative invasive cancer and followed up adequately, only 1 patient had local recurrence. The survival rate was $97 \%$ in patients with in situ carcinoma.

The survival rate was $91.6 \%$ without recurrence after a 5 -year follow-up and $95.8 \%$ including salvage surgery.

\section{Discussion}

Early-stage glottic cancers have a wide spectrum ranging from in situ carcinoma to bilateral tumors involving both cords without performing glottic fixation. The Classification of Malignant Tumors is insufficient for the determination of tumor localization and extension in early-stage glottic cancers. Although it is clear that the clinical behavior of a small millimetric tumor in the middle of the cord is different from that of a tumor extending along the whole length of the cord and leaning on the commissure, all of these tumors are included in the $\mathrm{T} 1$ a group in TNM.

Discussions on the optimal treatment of early-stage glottic tumors are still ongoing (10). In the literature, there are many studies reporting successful results at rates of $88-100 \%$ both through radiotherapy and through surgical techniques (10-21). In this series with 232 patients having early-stage glottic cancer, and treated with the laryngofissure cordectomy technique, the results of 167 patients who were followed up adequately were evaluated. The 5-year survival rate was $91.8 \%$ in these patients and $95.8 \%$ including salvage surgery cases. 
Radiotherapists suggest that phonation is protected better, the cost of treatment is lower, and tracheotomy is not required in these patients. However, this information is not completely accurate. Although the voice is better in patients receiving radiotherapy in the early stage, deterioration can be observed in the voice due to miosis and fibrosis that can develop in a year. Moreover, very good results have been reported for the quality of voice after reconstruction performed with band transposition after cordectomy (11).

The fear of tracheotomy prevents some patients from undergoing surgery. However, cordectomy has been performed without tracheotomy for more than 30 years in our clinic.

Another point that must be considered while making a choice between radiotherapy and surgery is the difficulty encountered in the determination of tumor stage through either indirect or direct laryngoscopy. Some tumors can be found to be at more advanced stages during operation, although they seem to be at early stages in laryngoscopy. Similarly, there are some tumors that can be inaccurately evaluated to be at an advanced stage because they impair cord movements as they have false glottic fixation and are high-volume. Despite the developments in computed tomography and magnetic resonance imaging techniques, there may be mistakes in staging (12).

In terms of the duration of treatment, while the duration of postoperative hospitalization is $2-3$ days, the duration of radiotherapy is 6-7 weeks.

Another important point is that while partial surgery can be repeated in salvage surgery for postoperative recurrences, total laryngectomy is needed in the occurrence of recurrence in patients receiving radiotherapy. It is difficult to predict tumor margins after radiotherapy because of this, and it is almost impossible to perform partial laryngectomy due to cartilage necrosis in the tissues given radiotherapy. In this study, partial laryngectomy was performed for protecting phonation in 7 of 14 patients after local recurrence.

In addition, it should be kept in mind that the mucosa is diseased in not only the cancerous region but also the whole region. The term "field cancerization" is the correct word to define this condition. Radiotherapy can remove cancer, but it does not improve the diseased mucosa (14). Therefore, in the presence of a second primary tumor, even if the tumor is so small that it can be partially removed, the only choice will be total laryngectomy. This is important particularly in young patients because they have a long life expectancy. It is likely that these patients have a second primary tumor and radiation-related tumors (15).

There are physicians who suggest that in case of failure, treatment can be repeated through partial laryngectomy by considering the first tumor (16). However, some other physicians suggest that anatomic barriers of the larynx get weaker after radiotherapy and that the minimal surgery should be total laryngectomy in case of failure in radiotherapy (17).
In cordectomy procedures performed with microlaryngoscopic techniques (laser or cold blade), survival rates have been reported to be over $90 \%(8,18-21)$.

What is more important is the absence of a piece for histopathological examination in the hand of a radiotherapist. In the study by Vahugan et al. (21), it was found in repeated biopsy that a tumor was completely removed in the first biopsy in $20 \%$ of patients diagnosed with cancer (21). In our series, it was reported that no tumor was found in postoperative pathological pieces in 22 patients $(9.5 \%)$, although all patients had been diagnosed with squamous cell carcinoma before surgery. Only dysplasia was detected in 18 patients (7.7\%). If these patients had undergone radiotherapy directly, they would have undergone radiotherapy unnecessarily.

The main principle of oncologic surgery is the complete removal of the tumor within adequate borders. If the tumor is left in the resection site, recurrence is inevitable. In cases where the tumor is found by a pathologist in the resection site, that is, the margin is positive, there are three alternatives. These alternatives are the wait-and-see approach, extension of resection borders with a second operation, and postoperative radiotherapy.

The wait-and-see approach is not accurate because there is tumor residue in the operation site. However, if the surgeon is sure of resection margins in a patient with a positive margin in one region, the patient can be closely followed up (22-25). Postoperative radiotherapy has been reported to have no effect on positive margins. The most appropriate action to be performed is the immediate extension of surgical margins. However, this decision is highly difficult, both for the physician and the patient.

In our study, a positive margin was found in 16 of 167 patients who were followed up. In 1 patient with three positive margins, the operation was re-performed, and near-total laryngectomy was performed.

In $7(43 \%)$ of 16 patients who underwent the wait-and-see approach, local recurrence developed. The development of recurrence was observed in only 7 (4.5\%) of 151 patients with negative margins. In the presence of positive margins, the frequency of recurrence development was found to be approximately 10 times higher, and this difference was statistically quite significant $(\mathrm{p}<0.001)$.

However, no negative effect was found on survival after salvage surgeries performed in patients with positive and negative margins. Wenig et al. (26) detected positive margins in 11 of 39 patients, and they reported the recurrence rate to be $55 \%$ in patients with a positive margin and $8 \%$ in patients with a negative margin. They reported that 1 patient with a positive margin (9\%) and 2 patients with negative margins $(8 \%)$ died due to the disease. They suggested that a positive margin had no effect on salvage. In our study, 3 (42\%) of 7 patients with a positive margin and recurrence and $3(50 \%)$ 
of 6 patients with a negative margin died. This supports that a positive margin has no effect on survival in patients who have undergone salvage surgery. Moreover, patients with a positive margin are followed up at more frequent intervals, and recurrences are noticed earlier.

Laryngofissure cordectomy is a technique that can be preferred for the treatment of early-stage glottic tumors because it has few complications, is cheap, and does not require tracheotomy. However, while planning a treatment, the physician should not decide alone; the patient should objectively be informed about all treatment opportunities, and the patient should be helped to decide by considering his/her occupation, general health conditions, treatment costs, and social status.

Ethics Committee Approval: Authors declared that the research was conducted according to the principles of the World Medical Association Declaration of Helsinki "Ethical Principles for Medical Research Involving Human Subjects", (amended in October 2013).

Informed Consent: Informed consent was not received due to the retrospective nature of this study.

Peer-review: Externally peer-reviewed.

Author Contributions: Concept - N.B.; Design - B.V.; Data Collection and/or Processing - B.V.; Analysis and/or Interpretation - B.V.; Literature Review - B.V.; Writing - B.V.; Critical Review - N.B.

Conflict of Interest: No conflict of interest was declared by the authors.

Financial Disclosure: The authors declared that this study has received no financial support.

\section{References}

1. Rothman KJ, Cann CI, Flanders D, Fried MP. Epidemiology of laryngeal cancer. Epidemiol Rev 1980; 2: 195-209.

2. Brauers (1834): Die bösartigen Neubildungen des Kehlkopfes. In denker A., O.Kahler. Handbuch der Hals-Nasen_Ohrenheilkunde, Bd. V. Springer ,Berlin, 1929 (p.441).

3. Alajmo E, Fini-Storchi O, Polli G. Five-year results of 1000 patients operated on for cancer of the larynx. Acta Otolaryngol 1976; 82: 437-9. [CrossRef]

4. Daly JF, Kwok FN. Laryngofissure and cordectomy. Laryngoscope 1975; 85: 1290-7. [CrossRef]

5. Danilidis J, Nikolaou A, Symeonidis V.Our experience in the surgical treatment of T1 carcinoma of the vocal cord. J Laryngol Otol 1990; 104: 222-4. [CrossRef]

6. Harwood AR, Hawkins NV, Keane T, Cummings B, Beale FA, Rider WD, et al. Radiotherapy of early glottic cancer. Laryngoscope 1980; 90: 465-70. [CrossRef]
7. Neel HB 3rd, Devine KD, Desanto LW. Laryngofissure and cordectomy for early cordal carcinoma: outcome in 182 patients. Otolaryngol Head Neck Surg (1979) 1980; 88: 79-84. [CrossRef]

8. Ossoff RH, Sisson GA, Shapshay SM. Endoscopic management of selected early vocal cord carcinoma. Ann Otol Rhinol Laryngol 1985; 94: 560-4.

9. Skolnik EM, Yee KF, Wheatley MA, Martin LO. Carcinoma of the laryngeal glottis therapy and end results. Laryngoscope 1975; 85: 1453-66. [CrossRef]

10. Osguthorpe JD, Putney FJ. Open surgical management of early glottic carcinoma. Otolaryngol Clin North Am 1997; 30: 87-99.

11. Fukuda H, Tsuji DH, Kawasaki Y, Kawaida M, Sakou T. Displacement of the ventricular fold following cordectomy. Auris Nasus Larynx 1990; 17: 221-8. [CrossRef]

12. Pillsbury HR, Kirchner JA. Clinical vs histopathologic staging in laryngeal cancer. Arch Otolaryngol 1979; 105: 157-9. [CrossRef]

13. Slaughter DP. Multicentric origin of intraoral carcinoma. Surgery 1946; 20: 133-46.

14. Gillis TM, Incze J, Strong MS, Vaughan CW, Simpson GT Natural history and management of keratosis, atypia, carcinoma-in situ, and microinvasive cancer of the larynx. Am J Surg 1983; 146: 512-6. [CrossRef]

15. Lund V, Sawyer R, Papavasiliou A Second respiratory tract carcinomas following radiotherapy to the larynx. Clin Oncol 1982; 8: 201-6.

16. Schwaab G, Mamelle G, Lartigau E, Parise O Jr, Wibault P, Luboinski B. Surgical salvage treatment of T1/T2 glottic carcinoma after failure of radiotherapy. Am J Surg 1994; 168: 474-5 [CrossRef]

17. Brandenburg JH, Condon KG, Frank TW. Coronal sections of larynges from radiation-therapy failures: a clinical-pathologic study. Otolaryngol Head Neck Surg 1986; 95: 213-8. [CrossRef]

18. Hirano M, Hirade Y. CO2 laser for treating glottic carcinoma. Acta Otolaryngol Suppl 1988; 458: 154-7. [CrossRef]

19. Lillie JC, DeSanto LW. Transoral surgery of early cordal carcinoma. Trans Am Acad Ophthalmol Otolaryngol 1973; 77: ORL92-6.

20. Shapshay SM, Hybels RL, Bohigian RK. Laser excision of early vocal cord carcinoma: indications, limitations, and precautions. Ann Otol Rhinol Laryngol 1990; 99: 46-50.

21. Vaughan CW, Strong MS, Jako GJ. Laryngeal carcinoma: transoral treatment utilizing the CO2 laser. Am J Surg 1978; 136: 490-3. [CrossRef]

22. Baker SR, Swanson NA. Complete microscopic controlled surgery for head and neck cancer. Head Neck Surg 1984; 6: 914-20. [CrossRef]

23. Bauer WC, Lesinski SG, Ogura JH. The significance of positive margins in hemilaryngectomy specimens. Laryngoscope 1975; 85: 1-13. [CrossRef]

24. Lee F, Perlmutter S, Ogura JH. Laryngeal radiation after hemilaryngectomy. Laryngoscope 1980; 90: 1534-9.

25. Looser KG, Shah JP, Strong EW. The significance of "positive" margins in surgically resected epidermoid carcinomas. Head Neck Surg 1978; 1: 107-11. [CrossRef]

26. Wenig BL, Berry BW Jr. Management of patients with positive surgical margins after vertical hemilaryngectomy. Arch Otolaryngol Head Neck Surg 1995; 121: 172-5. [CrossRef] 